\title{
The Distribution of Fishing Revenues Among North Pacific Regions and Communities
}

\author{
CHRISTOPHER M. ANDERSON, JENNIFER MEREDITH, \\ RONALD G. FELTHOVEN, and MICHAEL FEY
}

\section{Introduction}

The U.S. North Pacific fisheries off the coast of Alaska generate approximately $\$ 2$ billion in ex-vessel revenues each year (NMFS, 2017). This income has been reported publicly for decades by federal and state annual reports (Fissel et al., 2015), but typically in a manner that attributes revenues to particular species, gear types, or broad areas within the North Pacific (e.g., Bering Sea, Gulf of Alaska). This study uses data on vessel ownership and residency to link the earnings from these fisheries to the individual cities and states in which harvesters live and likely spend their fishing returns.

Christopher A. Anderson is Associate Professor at the University of Washington School of Aquatic and Fishery Sciences, 1122 NE Boat St., Seattle, WA 98105. Jennifer Meredith is an Assistant Professor in the Economics Department at Colby College, 5230 Mayflower Hill, Waterville, ME 04901. Ronald G. Felthoven is Director of the Resource Ecology and Fisheries Management Division at the Alaska Fisheries Science Center, National Marine Fisheries Service, NOAA, 7600 Sand Point Way NE, Seattle WA 98115. Michael Fey is a data manager for the Pacific States Marine Fisheries Commission, Alaska Fisheries Information Network, 205 SE Spokane St., Portland, OR 97202

doi: https://doi.org/10.7755/MFR.80.2.1
We also provide a detailed accounting of where the earnings from federally managed fisheries off Alaska flow. It provides a new and unique perspective on which fishing fleets generate the greatest revenues, describes the geographic location of vessel and quota owners in these fisheries, and analyzes various dimensions along which the distribution of fisheries revenues may have changed over the past decade in response to new management initiatives. We examine trends in fishery diversification within regions and across population size groups for fishing communities.

Since passage of the MagnusonStevens Fishery Management and Conservation Act in 1976, the North Pacific Fishery Management Council (Council) has actively managed most of the fisheries occurring in federal waters off the coast of Alaska, in conjunction with the U.S. Department of Commerce. North Pacific fisheries have a strong record of sustainable management and were among the first U.S. fisheries to adopt management programs that utilized individual fishing quotas and cooperatives (hereafter "catch shares") with an objective to end the race for fish, and achieve economic and social goals (NPFMC, 2016b). The specific management approaches and objectives within these programs vary by fishery, a result of a complex public management process rather than a singular, unified strategic plan. That said, the general structure of many fisheries has gradually been tightened to "enclose" the fisheries and provide a more stable set of participants and quota allocations to specific groups (Holland, 2000). Often this begins with the implementation of limited entry rules which eliminate the creation of new permits or make it difficult for entry into a fishery.

License limitation programs follow, which further define the set of eligible vessels or individuals who may participate and, more specifically, define the nature of their eligibility. This degree of partitioning allows managers to then define catch histories, a set of eligible entities, and quota allocations which form the basis of a catch share program. In addition to improving economic efficiency and promoting sustainable harvest, socioeconomic objectives were often explicitly incorporated into the catch share programs.

Many of these programs in the North Pacific strive to strike a balance between increasing the economic success of incumbent harvesters and proces-
ABSTRACT-Our study uses data on vessel ownership and residency to link the earnings from North Pacific fisheries to the individual communities, cities, and states in which harvesters live and likely spend much of their fishing returns. We provide perspective on which fishing fleets generate the greatest revenues, describe the geographic location of vessel and quota owners in these fisheries, and analyze changes in the distribution of fisheries revenues over the past decade in re- sponse to new management initiatives. We examine trends in fishery diversification for fishing communities within regions and across population size. Our results suggest greater complexity than some of the literature and stakeholder sentiment which argue that limited access and catch share programs cause small fishing-dependent communities to lose revenue. Using data from 2004 to 2013, we find no consistent trend of revenue or transfer of vessels from rural Alaska to Seattle, nor revenue con- solidation away from smaller towns toward larger cities. We find that some regions are increasingly concentrated and reliant on the revenue generating capacity of a smaller vessel fleet. This trend is likely a result of consolidation in the number of harvesting operations. We also discuss the set of factors specific to management programs in the North Pacific that may have limited spatio-temporal revenue redistribution across community size or region following rationalization. 
sors (whose capital is predominantly located in Seattle), while assuring adequate support for Alaska communities historically involved in commercial or subsistence fisheries. As a result, major North Pacific fisheries present the opportunity to observe the impact of catch share programs on aggregate performance and distributional outcomes in the short and medium term.

Various narratives have emerged regarding the consequences of enclosure policies and subsequent privatization of a public resource through catch share programs (Costello et al., 2008; Thebaud et al., 2012; Scheld and Anderson, 2014; Holland et al., 2017). These policies grant valuable secure access privileges to incumbent harvesters, which then present incentives to reduce costs and improve product forms, increasing efficiency and profitability. In doing so, however, they may also present a financial barrier for younger fishermen looking to advance their careers through ownership; the more successful the program at generating profits, the larger the purchase price for quotas and thus, difficulty entering the fishery (van Putten and Gardner, 2010).

Catch shares may also facilitate consolidation, lowering the aggregate costs of harvesting the annual quota, and in turn increasing economic efficiency (e.g., Bering Sea crab rationalization (NPFMC, 2016a)). However, such consolidation may displace crew jobs or change the nature of the remaining jobs to one in which they buy quota from quota owners and harvest it on others' behalf (Abbott et al., 2010). This study does not focus broadly on the general effects of catch share programs; instead, we examine ways in which the geographic participation and earnings of historically engaged regions may have changed after the new regimes were instituted.

Specifically, we use annual vessellevel data on federal fishery participants from 2004 to 2013 to describe shifts in the earnings from Alaska's fisheries, with a focus on the regional distribution of fisheries revenues, as represented by the owner address of federal vessel licenses. During this period, we observe the medium-term effects of several large fisheries that implemented catch share systems in the mid- and late 1990's (halibut, Hippoglossus hippoglossus; sablefish, Anoplopoma fimbria; and walleye pollock, Gadus chalcogrammus).

We are unable to observe the initial impact of the catch share programs for halibut, sablefish, and pollock or the limited entry permit system established for Pacific salmon, Oncorhynchus spp., in 1975, so if consolidation of ownership occurred rapidly and then stabilized in these fisheries this will not be reflected in our data. We also see the short-term effects of fisheries that implemented catch share systems soon after the beginning of our data series. These fisheries include the crab fisheries (which target red king crab, Paralithodes camtschaticus; blue king crab, Paralithodes platypus; golden king crab, Lithodes aequispinus; opilio crab, Chionoecetes opilio; and Tanner crab, Chionoecetes bairdi), the rockfish fishery (which catches mainly rougheye, Sebastes aleutianus; shortraker, Sebastes borealis; and thornyhead, Sebastolobus alascanus), the non-pollock trawl catcher-processor fleet (which targets mainly Pacific cod, Gadus microcephalus; yellowfin sole, Limanda aspera; flathead sole, Hippoglossoides elassodon; rock sole, Lepidopsetta bilineata; and Atka mackerel, Pleurogrammus monopterygius), and many other fisheries which remain in legacy management.

By looking at a range of fisheries under different management regimes, we can explore whether there appear to be systematic differences in the revenue distribution among different management regimes. We first examine the distribution of revenue by vessel owner region and then discuss trends in regional diversification and concentration. The following section continues this same focus, but does so by community size to see if smaller or larger populations tend to be more susceptible to change over time. We conclude with a summary and discussion of our findings.

\section{Approaches for Examining Distributional Impacts in Alaska Fisheries}

Characterizing the effects of enclosure policies on fisheries and fishing-dependent communities has been approached from multiple disciplines and at different scales. Here we will discuss some previous studies and their approaches, followed by a description of the insights we hope to glean and the specific questions we plan to address. Although where relevant we attempt to draw inferences regarding the spatial redistributional effects of catch share programs, our analysis should not be perceived as an attempt to evaluate the overall effects of these programs. Readers are advised to peruse the literature discussed below and beyond.

At the community level, Carothers (2008) uses ethnographic methods to illuminate the linkage between transferable access rights, in the form of limited-access salmon permits, and a reduction of fishing activity within Aleutian Island communities. She argues that consolidation in the processing industry, away from small communities and into regional hubs, has removed a common source of personal credit which increases residents' vulnerability.

Monetized fishing access rights thus become a primary source of emergency credit for rural harvesters who experience personal financial shocks. Although strongly place-identified, they are rarely able to repurchase the permit and resume fishing, with the concomitant reduction of local crewing and support jobs from their rural communities; the community-level benefits of these jobs are not fully internalized as part of the private decision to sell.

This dynamic is consistent with the state-wide pattern of smaller communities being more likely to divest of halibut Individual Fishing Quota (IFQ) in the years immediately following the 1995 inception of the program (Carothers et al., 2010). However, Sethi et al. (2014a) use a suite of eco- 
nomic indicators to show that permit and quota sales are not leading to a broad-scale reduction in fishing revenue associated with small communities over the period 1980-2010. Integrating across fisheries, they find that despite the stability in overall revenue, there are fewer fishermen and they participate in fewer fisheries, a trend also observed across West Coast federal fisheries (Holland and Kasperski, 2016).

This consolidation may increase vulnerability to management and natural fluctuations, such as climate change (e.g., Himes-Cornell and Kasperski, 2016). There is evidence that reductions in community diversification increase volatility in fishing revenues, but also that community portfolios are largely predetermined by location and thus unable to be influenced by management shifts (Sethi et al., 2014b). Reduced community-level economic dependence on fisheries primarily reflects growth in other sectors or the introduction of catch share programs that decrease community diversification in exchange for the stabilization of revenue (Holland and Kasperski, 2016).

Gho et al. (2012) use Alaska state fisheries permits data (in contrast to our federal fishery focus here) to examine changes in the age and geographic distribution of permit holders. They differentiate geographic changes attributable to permit transfers among parties living in different areas as well as relocation of a given permit holder. They also categorize the nature of the transfers in terms of what fraction were transferred to family, friends, or other, as well as according to the type of area to which the permit is tied (e.g., rural local and urban non-local). They find an overall net decline of 2,203 permits when examining the distribution of Alaska rural local permits from 1975 to 2010. However, rates of change for individual permit types have varied considerably over the time series. They also find the average age of permit holders to have increased in aggregate, again with some exceptions in specific fisheries.
This study uses the fishing revenue component included in Sethi et al. $(2014 a, b)$ to characterize changes in the distribution of earnings from North Pacific fisheries in the context of each fishery's enclosure policies. Additionally, however, we track regional changes and expand the focus to all communities that benefit from North Pacific fisheries, including those outside Alaska. Further, we use vessellevel data to decompose the revenue by fishery, capturing not just aggregate shifts, but shifts between fisheries within each region.

We explore three leading narratives about how enclosure and rationalization are affecting the distribution of, and variation in, fisheries revenues. First, we examine whether revenue in key fisheries is shifting among regions. This analysis illustrates the extent to which the small community processes presented in Carothers (2008) are leading to a broad-scale shift in fishing activity out of coastal Alaska, or Alas$\mathrm{ka}$ as a whole, toward other regions.

Second, we evaluate whether small communities, as a category, are receiving a decreasing share in fishery revenues. Finally, we examine how individual vessels are altering the extent of their participation in individual fisheries. In particular, we look at whether vessels are becoming more dependent on fewer fisheries, and thus more exposed to fluctuations in individual stocks or management plans (Kasperski and Holland, 2013).

Understanding whether and how revenue distributions evolve is important because managers or stakeholders may have preferences over the distribution of benefits within their jurisdiction. For example, some rationalization programs (such as the Pacific Halibut and Sablefish IFQ Program) have had explicit management goals of retaining a local owner/operator fleet. In our examination of aggregate revenue by region, fishery, and community size, we find considerable stability over the period 2004-13. We find little evidence of ongoing change for both the set of mature enclosure programs and the most recent rationalization programs. However, this observed stability is likely the result of policy efforts to minimize such impacts, as the most prominent trends in the data are associated with Community Development Quota (CDQ) group activity preventing erosion of, and in some cases increasing, the extent and breadth of fishery participation in coastal Alaska communities.

\section{North Pacific Fisheries Overview}

Table 1 presents the 18 fleets of vessels on which we focus our analysis, including 16 fleets managed by the North Pacific Fishery Management Council (NPFMC, 2012), and 2 fleets managed by the State of Alaska. We have ordered the vessel groups according to average annual revenue over the period of 2004-13. Most vessels in these fleets participate in multiple fisheries throughout the year, and some participate in fisheries in other regions. ${ }^{1}$ Since these fleets are overlapping, the data reported in Table 1 reflects statistics for all vessels that reported landings within the fishery and common overlapping fleets are shown in the final column.

Pollock, by far the largest fishery in the United States by landings (NMFS, 2017), has the largest total revenue, split among catcher vessel (inshore), catcher-processor, and mothership fleets that manage collective allocations through cooperatives (Felthoven, 2002). The crab fisheries, collectively, exhibit the second highest average federal fisheries revenue after pollock;

${ }^{1}$ As such, the "fleet" designation for the vessels reflects either the catch share program in which they are included or the predominant catch portfolio and gear type exhibited by the vessels. The "management style" pertains to whether the fishery is managed using catch shares (with specific quantities or shares of the total allowable catch going to individuals or groups) or another mechanism such as limited entry (in which the universe of eligible participants is strictly defined, but the allocation of catch for each participant is not). Some catch share programs function with individual quota holders as the management unit, while others operate as cooperatives; however, cooperatives have even formed in some of the limited entry fisheries with a manageable number of vessels. More information on these fleets can be found in NPFMC (2012). More specificity about the nature of quota allocations and transferability of the catch share fisheries is included in Holland et al. (2015). 


\begin{tabular}{|c|c|c|c|c|c|c|c|}
\hline Fleet description & $\begin{array}{c}\text { Avg. share of } \\
\text { annual revenue } \\
\text { to } \mathrm{AK}^{1} \\
\end{array}$ & $\begin{array}{l}\text { Avg.Value } \\
\text { \$M } \\
\text { (Std Dev) }\end{array}$ & $\begin{array}{c}2010 \\
\text { Landings } \\
\text { (Mlbs) }\end{array}$ & $\begin{array}{l}2013 \\
\text { Active vessels }\end{array}$ & $\begin{array}{l}\text { Management style, quota } \\
\text { share (QS) allocation method } \\
\text { for catch shares, (year } \\
\text { implemented) }\end{array}$ & $\begin{array}{l}\text { Current management } \\
\text { actions or issues }\end{array}$ & $\begin{array}{c}\text { Common Overlapping } \\
\text { fisheries }^{2}\end{array}$ \\
\hline $\begin{array}{l}\text { BSAI Crab } \\
\text { Catcher vessels and catcher-processors targeting } \\
\text { various species of crab with pot gear in the Bering Sea }\end{array}$ & 28.13 & $\begin{array}{l}191.87 \\
(53.80)\end{array}$ & 72.40 & $\begin{array}{l}114 \text { (282 in } 2004 \\
\text { pre-IFQ) }\end{array}$ & $\begin{array}{l}\text { Catch share; QS to } \\
\text { individuals, can operate as } \\
\text { co-op (2005) }\end{array}$ & $\begin{array}{l}\text { ROFO Participation and } \\
\text { voluntary lease rate caps }\end{array}$ & Pot, Salmon tendering \\
\hline $\begin{array}{l}\text { AFA Catcher Vessels } \\
\text { BSAl pelagic trawl pollock delivered inshore }\end{array}$ & 1.49 & $\begin{array}{l}179.44 \\
(27.22)\end{array}$ & 890.67 & 84 & $\begin{array}{l}\text { Catch share; QS to group, do } \\
\text { operate as co-op (1999) }\end{array}$ & Chinook salmon bycatch & $\begin{array}{l}\text { Central Gulf Trawl, Pacific } \\
\text { Hake }\end{array}$ \\
\hline $\begin{array}{l}\text { Halibut IFQ } \\
\text { Longline catcher vessels targeting halibut in GOA and } \\
\text { BSAl }\end{array}$ & 68.52 & $\begin{array}{l}175.30 \\
(35.04)\end{array}$ & 52.55 & $\begin{array}{l}910(\max \text { of } 1471 \\
\text { in 2004) }\end{array}$ & $\begin{array}{l}\text { Catch share; QS to } \\
\text { individuals (1995) }\end{array}$ & $\begin{array}{l}\text { Declining biological } \\
\text { availability }\end{array}$ & Salmon, Sablefish \\
\hline $\begin{array}{l}\text { AFA Catcher-processor } \\
\text { BSAl pelagic trawl pollock harvested and processed } \\
\text { on board }\end{array}$ & 7.82 & $\begin{array}{l}143.59 \\
(40.96)\end{array}$ & 313.73 & 16 & $\begin{array}{l}\text { Catch share; QS to group, do } \\
\text { operate as co-op (1999) }\end{array}$ & Chinook salmon bycatch & Pacific Hake \\
\hline $\begin{array}{l}\text { State Salmon } \\
\text { Landings of salmon by vessels also participating in at } \\
\text { least one Federal fishery }\end{array}$ & 93.11 & $\begin{array}{l}125.43 \\
(28.87)\end{array}$ & 225.19 & $\begin{array}{c}683(\max \text { of } 814 \text { in } \\
2005)\end{array}$ & Limited Entry (1973) & $\begin{array}{l}\text { Volatility in landings and } \\
\text { prices }\end{array}$ & Halibut IFQ \\
\hline $\begin{array}{l}\text { Amendment } 80 \\
\text { BSAl trawl catcher-processors not targeting pollock. } \\
\text { Mainly targeting flatfish and Pacific cod or rockfish and } \\
\text { Atka mackerel. }\end{array}$ & 0 & $\begin{array}{l}114.02 \\
(29.27)\end{array}$ & 162.86 & $\begin{array}{l}19(23 \text { in } 2004 \\
\text { pre-A80) }\end{array}$ & $\begin{array}{l}\text { Catch share; QS to } \\
\text { individuals, do operate as } \\
\text { co-op (2008) }\end{array}$ & Halibut PSC reductions & Central Gulf Trawl \\
\hline $\begin{array}{l}\text { Sablefish } \\
\text { Fixed gear catcher vessels and catcher-processors } \\
\text { predominantly targeting sablefish }\end{array}$ & 50.9 & $\begin{array}{l}83.76 \\
(16.70)\end{array}$ & 25.11 & $\begin{array}{c}354(\max \text { of } 426 \text { in } \\
2004)\end{array}$ & $\begin{array}{l}\text { Catch share; QS to } \\
\text { individuals (1995) }\end{array}$ & $\begin{array}{l}\text { Addition of pots, seabird } \\
\text { takes }\end{array}$ & Halibut IFQ, Salmon \\
\hline $\begin{array}{l}\text { Catcher-processor Hook and Line } \\
\text { Freezer longliners targeting BSAl and GOA Pacific cod }\end{array}$ & 21.7 & $\begin{array}{r}56.75 \\
(16.63) \\
\end{array}$ & 231.76 & 35 & $\begin{array}{l}\text { Limited Entry; operate as co- } \\
\text { op (2006) }\end{array}$ & $\begin{array}{l}\text { Halibut PSC and seabird } \\
\text { takes }\end{array}$ & Sablefish \\
\hline $\begin{array}{l}\text { Central Gulf of Alaska Trawl } \\
\text { Catcher vessels and catcher-processors primarily } \\
\text { targeting flatfish, pollock, Pacific cod, and rockfish }\end{array}$ & 33.41 & $\begin{array}{c}37.62 \\
(11.05)\end{array}$ & 218.80 & 66 & $\begin{array}{l}\text { Limited Entry (2000) except } \\
\text { catch share Central GOA } \\
\text { Rockfish (2007) }\end{array}$ & $\begin{array}{l}\text { Halibut PSC reductions, } \\
\text { rockfish quota program }\end{array}$ & AFA Catcher Vessels \\
\hline $\begin{array}{l}\text { AFA Mothership } \\
\text { BSAl trawl pollock delivered to mothership and } \\
\text { processed on board }\end{array}$ & 7.04 & $\begin{array}{l}37.47 \\
(4.37)\end{array}$ & 155.01 & 14 & $\begin{array}{l}\text { Catch share; QS to } \\
\text { individuals, do operate as } \\
\text { co-op (1998) }\end{array}$ & Chinook salmon bycatch & $\begin{array}{l}\text { AFA Catcher Vessels, } \\
\text { Pacific Hake }\end{array}$ \\
\hline $\begin{array}{l}\text { Groundfish Pot } \\
\text { Catcher vessels and catcher-processors using pot gear } \\
\text { primarily to target BSAl/GOA Pacific cod }\end{array}$ & 50.33 & $\begin{array}{l}27.46 \\
(8.20)\end{array}$ & 131.10 & $\begin{array}{c}126(\max \text { of } 149 \text { in } \\
2007)\end{array}$ & $\begin{array}{l}\text { Limited Entry (2000) - in } \\
2009 \text { gear-specific co-ops } \\
\text { established }\end{array}$ & Halibut and crab quota & Halibut IFQ, Crab, Salmon \\
\hline $\begin{array}{l}\text { Western Gulf of Alaska Trawl } \\
\text { Catcher vessels and catcher-processors primarily } \\
\text { targeting flatfish, Pacific cod, pollock, and rockfish }\end{array}$ & 33.59 & $\begin{array}{l}11.92 \\
(2.87)\end{array}$ & 91.52 & 40 & Limited Entry (2000) & Halibut PSC reductions & $\begin{array}{l}\text { Salmon, Central Gulf Trawl, } \\
\text { Halibut IFQ, A80 }\end{array}$ \\
\hline $\begin{array}{l}\text { Non-AFA BSAl Trawl } \\
\text { Catcher vessels primarily targeting Pacific cod with } \\
\text { bottom trawls }\end{array}$ & 4.1 & $\begin{array}{l}10.26 \\
(5.94)\end{array}$ & 43.87 & 14 & Limited Entry (2000) & Halibut PSC reductions & $\begin{array}{l}\text { Central Gulf Trawl, Western } \\
\text { Gulf Trawl }\end{array}$ \\
\hline $\begin{array}{l}\text { Catcher Vessel Hook and Line } \\
\text { Groundfish longline catcher vessels predominantly } \\
\text { targeting Pacific cod }\end{array}$ & 89.35 & $\begin{array}{l}6.57 \\
(2.02)\end{array}$ & 19.05 & $\begin{array}{l}66(\max \text { of } 96 \text { in } \\
2008)\end{array}$ & Limited Entry (2000) & Halibut PSC reductions & $\begin{array}{l}\text { Salmon, Sablefish, Halibut } \\
\text { IFQ }\end{array}$ \\
\hline $\begin{array}{l}\text { Scallop } \\
\text { Catcher vessels targeting weathervane scallop using } \\
\text { dredges }\end{array}$ & 5.65 & $\begin{array}{l}3.62 \\
(0.94)\end{array}$ & 0.46 & 5 & \begin{tabular}{|l} 
Limited Entry (1999) - in \\
2000 co-op established \\
moratorium on permits (1997)
\end{tabular} & $\begin{array}{l}\text { Ecosystem effects of } \\
\text { dredging }\end{array}$ & Non-AFA BSAI Trawl, Crab \\
\hline $\begin{array}{l}\text { Jig } \\
\text { Catcher vessels using jig gear (actively fished vertical } \\
\text { lines) and predominantly targeting BSAl/GOA Pacific cod }\end{array}$ & 91.78 & $\begin{array}{l}0.39 \\
(0.24)\end{array}$ & 8.45 & (max of 251 in 2012) & $\begin{array}{l}\text { Limited Entry (2000); } \\
\text { operate as co-op }\end{array}$ & Halibut quota & Halibut IFQ, Salmon \\
\hline
\end{tabular}

lines) and predominantly targeting BSAl/GOA Pacific cod

${ }^{1}$ Average of 2004-13 annual percentage of fleet's total revenue attributed to vessels with CFEC owner addresses within Alaska

${ }^{2}$ Other fisheries where vessels from a given fleet are likely to participate. 
their revenue share in Alaska has been trending upwards since the implementation of a catch share program in 2005 (NPFMC, 2016a).

The IFQ halibut fishery, rationalized with sablefish in 1995, has revenues comparable to the shoreside pollock fishery, although revenue has been declining along with decreasing stock levels exhibited over the last decade. Despite the high degree of natural fluctuation in individual river systems, the large limited-entry state salmon fishery contributes significantly to the fishing portfolios of communities throughout Alaska; note however that, as stated earlier, our study considers only the salmon caught by vessels that also fish in federal fisheries (as salmon is managed by the state and those vessels which just fish in state fisheries are not included here).

Revenue from the Amendment 80 groundfish trawl fleet has steadily increased since cooperative-based rationalization in 2008. The IFQ sablefish fishery is a medium-sized fishery with stable revenues. In comparison, the remaining fisheries such as scallop, Central Gulf trawl, and groundfish pot or longline are all relatively small in total revenue; however, many fisheries play significant roles in their regions' economies.

One component of fisheries management in Alaska worth noting is the annual set aside of CDQ for several groundfish and crab species harvested in Alaska. The CDQ corporations were first established by the NPFMC in 1992 and then made permanent under reauthorization of the Magnuson-Stevens Act in 1996 in order to represent the fishing interests of western Alaska's regional coastal communities. Six regional CDQ groups in western Alaska receive allocations for a portion of the total allowable catch (TAC) for groundfish, crab, halibut, sablefish, and prohibited species (PSC).

Typically, around $10 \%$ of the TAC is set aside. In some areas, however, up to $100 \%$ of the TAC is set aside for CDQ halibut, and up to $20 \%$ for fixed-gear CDQ sablefish. The 2017 allocations can be viewed at https://alaskafisher- ies.noaa.gov/sites/default/files/reports/ annualmatrix 2017.pdf. Aside from the higher proportion of the halibut and sablefish TACs set aside for CDQ, the nature of these fisheries differs markedly from the way CDQ allocations are fished in more industrialized fleets made up of larger vessels based out of Seattle (Szymkowiak and Himes-Cornell, 2018).

In the crab and groundfish fleets, CDQ is primarily leased by these vessels and fished alongside their nonCDQ allocation. Alternatively, in the halibut (and sablefish) fisheries, the CDQ is more likely to be fished by vessels owned by the residents of CDQ regions who do not have meaningful participation in any other federal fleet. Several CDQ groups have been successful in leveraging their allocations into ownership shares in crab and groundfish vessels, with those CDQ landings occurring alongside non-CDQ landings and within overlapping fleets (American Fisheries Act and Amendment 80). For purposes of this study, we examined only one specific CDQ halibut fleet but note the significance of CDQ for various fleets and regions when relevant.

In most fisheries we examined, real revenue has been increasing, reflecting management that sets catch at sustainable levels, and improved handling and higher-valued product forms facilitated in many cases by eliminating the race for fish. However, pollock experienced a downturn in 2009-10, mostly attributable to small year classes among the 3 - to 8-yr-olds typically targeted. Revenue has not yet returned to abundant 2008 levels. Salmon product forms have improved to maintain recent average price levels among increasing competition from aquaculture (Knapp et al., 2013). Revenue from halibut has dramatically fallen as the stock, which is managed under treaty by the International Pacific Halibut Commission (IPHC), has seen biomass and size-at-age decline since 2004 (for reasons not fully understood and not necessarily associated with the fishery), leading to a $63 \%$ reduction in
IFQ halibut quotas between 2004 and 2013 (NMFS/AKRO, 2016b).

Importantly, most of these revenue gains are from market improvements, as most North Pacific fish stocks have been healthy and relatively stable throughout this period. Thus, total harvest has not increased. In the Bering Sea/Aleutian Islands, total harvest has been constrained throughout this period by a longstanding "ecosystem cap" of 2 million t (Witherell et al., 2000). Although the sum of species-specific Allowable Biological Catches (ABC) has been in the 3-3.5 million $t$ range, the Council issues TACs totaling only 2 million $t$ each year, to introduce a buffer so most TACs do not fluctuate with natural variation in their stocks. A similar cap of 800,000 t exists for the Gulf of Alaska, though total ABCs have stabilized just below it.

\section{Fishery Revenue Data}

The confidential data used in our analysis was provided by the Alaska Fisheries Information Network (AKFIN), an interagency organization that maintains fisheries data derived from NMFS and the State of Alaska sources (including the electronic fish tickets). When fish or shellfish are caught and sold to the first buyer, the buyer enters information into the state of Alaska's eLandings database and generates an electronic "fish ticket." These tickets reflect the landing vessel, species, quantity, and ex-vessel prices for shoreside fisheries, allowing computation of ex-vessel revenue estimates for each delivery. Catcher-processor data reports the value of all products produced from the raw fish and thus reflect value added from primary processing. To generate consistent estimates of ex-vessel value across both catcher vessel and catch-processor fleets, NMFS utilizes a two-step procedure in order to impute the ex-vessel value of the fish used to create the catcher-processor products (Fissel et al., 2015).

To create the distinct fleets discussed in this manuscript, AKFIN staff analyzed each vessel's landing patterns and permit holdings to determine the 
fishery in which it was participating at the time fish were landed. It can be difficult to associate landings within a fishery because the same species can be landed either through directed targeting under one management plan or as bycatch when the same vessel is targeting other species. For example, some Amendment 80 groundfish fleet vessels can participate in directed fishing for Pacific cod, but also they can land a "maximum retainable amount" of Pacific cod as a percentage of flatfish (Pleuronectiformes) when targeting flatfish. In addition to these interlinked federal fisheries, we consider these vessels' landings in the state-managed salmon and "other state" fisheries within 3 n.mi. of shore. AKFIN does not have data on participation in fisheries outside the Alaska management regions (e.g., American Fisheries Act (AFA) pollock vessels also catch Pacific whiting, Merluccius productus, off Oregon and Washington), or information on non-fishing revenue (such as tendering in various salmon fisheries), so we focus exclusively on participation in the fisheries off Alaska. Our dataset was limited to 2004-13 because the process of associating landings within fleets could only be completed reliably for these years of data when this research was undertaken.

We use the total annual revenue each vessel derives from each fishery in which it participates to assess temporal changes in the regional and community-scale distribution of fishing revenues. We focus on revenue because it is available for all fishing fleets, but we recognize that there are limitations to this variable, such as changes in costs or added value. Costs may vary significantly on a decadal scale as people and capital move among regions and fisheries and efficiency-enhancing rationalization programs are introduced; therefore, we are unable to conduct a formal welfare analysis that would instead calculate net benefits of the harvest sector. Additionally, ex-vessel revenue does not capture value added through processing, which can be significant depend- ing on the product form. However, examining changes in processing plant volume and locations is beyond the scope of the current study.

To associate a vessel's revenue with a region, we use the "vessel owner city" field maintained by the Commercial Fisheries Entry Commission (CFEC) when vessel owners file for their vessel license each year. ${ }^{2}$ This variable is primary, and prevalent, in that it was missing for only 38 of the 18,370 total observations. The vessel owner's city is not necessarily reflective of where the majority of fish is landed, or where the vessel spends the majority of its time; however, it is suggestive of where the ownerwho collects the largest share of fishing income-spends income, and may also reflect where the vessel purchases some supplies and hires crew. We recognize this proxy may not be representative of where all the crew factor payments flow, but it is the best indicator at our disposal.

An additional concern is that attributing revenue to vessel owners may inflate the actual benefits accruing to the vessel owner's community when the vessel owner is not the same as the quota or permit owner, as may be the case when emergency transfers, hired masters, or outright leasing provisions are common. Approximately $40 \%$ of vessels in the halibut fleet and $55 \%$ of vessels in the sablefish fleet reported using hired masters, and many use emergency medical transfers to bypass owner-on-board requirements (NPFMC, 2016b). Anecdotally, in the halibut and sablefish fisheries lease rates range from $50 \%$ to $60 \%$ of gross revenue (NPFMC, 2016b) and empirically, lease rates range from $30 \%$ to $65 \%$ of gross revenue in the

${ }^{2}$ AKFIN provides an alternative, vessel hailing port, which is a landings-based estimate of the vessel's home port. This variable had 3,059 missing vessel years (almost entirely non-federal vessels), and after conducting our analysis with both variables we did not observe a statistically different distribution of aggregate revenues across regions. For this reason, as well as brevity and greater data availability, we have restricted our discussion to results based upon vessel owner city, with additional figures based upon hailing port residing in our appendix. crab fishery (NPFMC, 2016a) which means considerable revenue accrues to quota owners, rather than vessel owners. Despite the large share of ex-vessel revenue that accrues to the quota owner, the proportion of vessels that lease quota is relatively stable over the course of our study (NPFMC 2016a, b) which means changes in leasing prevalence are not driving our results.

The relationship between the registered vessel owner's city and local benefits may also be weaker for corporate-owned vessels, typical of industrial fleets, where the profits from the corporation are distributed among many individuals in different localities. Neither NOAA nor CFEC maintain data on individual ownership of corporate entities, prohibiting disaggregation of these revenues. An important exception is when vessels are owned by regional CDQ groups. The CDQ groups use revenue from fishing or leasing the quota to reinvest in community fishing involvement, as well as the education and welfare of their community members. Because CDQ groups disclose their vessel ownership interest in their annual reports, we are able to associate those vessels' revenues with the CDQ regions.

\section{Regional Revenue Distribution}

The second column of Table 1 lists the percentage of fishery revenue earned by vessel owners residing in Alaska; this varies widely by fishery. Four of the largest fisheries were never operated out of Alaska. The AFA catcher vessel, catcher-processor, and mothership pollock fleets, the Amendment 80 non-pollock groundfish fleet, and the cod freezer-longliners were almost entirely developed with Washington State capital - or foreign capital that moved to Washington following the American Fisheries Act. In contrast, Gulf of Alaska groundfishing, jigging, and state fisheries-especially salmon - are strongly rooted to Alaska ownership, and have been historically pursued by residents of small and medium-sized Alaska communities.

In between, crab, halibut, and inshore pollock have significant own- 
ership interests inside and outside Alaska. These different geographies of ownership can lead to conflicts among fleets when they catch the same species. For example, significant management effort focuses on balancing the distribution of Chinook salmon between the Alaska directed salmon fisheries and bycatch by the predominantly Washington pollock fleet (NMFS/AKRO, 2016a). A similar tension exists between halibut caught by the Alaska IFQ/CDQ fleet and halibut caught incidentally by the primarily Washington-based Amendment 80 fleet in their pursuit of groundfish (NMFS/AKRO, 2016a).

To analyze movement of fishing revenues, we identify a set of regions with significant representation in the North Pacific Fisheries. In Western Alaska, we use CDQ Program region boundaries to define the regions: we pool Coastal Villages and Yukon Delta regions as AK Central West due to the very small number of observations. The AK Aleutians and Pribilofs region pools the revenue from Saint Paul Island's Central Bering Sea Fishermen's Association (CBSFA) with communities located within the boundaries of the Aleutian Pribilof Island Community Development Association (APICDA). We also include Kodiak, Anchorage/Matsu, Cook Inlet/Prince William Sound, and Southeast as distinct regions, along with Other Alaska. Outside of Alaska, we distinguish the Seattle Metropolitan Statistical Area (MSA), Other Washington, Oregon, California, and Other States.

Figure 1 shows the distribution of revenue from individual fleets, by residence of the harvesting vessel owner. Within each region, the left pie chart shows the average revenue contribution from each fishery in 2004 through 2006, and the right pie reflects revenues from 2011 through 2013; the areas of the pie are proportional to the region's share of total North $\mathrm{Pa}$ cific fishery revenue during each time period.

Seattle MSA is dominant in all years, whereas some regions, such as Alaska Other and those in western
Alaska, have such a small share of revenue that the inset shows the individual fisheries. Between the two time periods, real revenues in all regions grew an average of $7 \%$. Some regions grew more than others, including Seattle MSA, Anchorage/MatSu, and Norton Sound. Total revenue fell in regions such as Southeast, Bristol Bay Lakes/ Peninsula, and Other Washington.

Looking within regions across time, the shoreside and catcher-processor pollock fleets dominate Seattle MSA revenue, and their regional revenue share remained stable. Increasing revenues from the Amendment 80 groundfish fleet increased its share of income associated with Seattle, as well as other U.S. regions outside the Pacific Northwest. Owners from both Oregon and Kodiak, Alaska, are increasingly involved in the Central Gulf trawl fleet and rationalized crab, while reducing their dependence on halibut IFQ revenue. Share of revenue from halibut IFQ reduced across almost all regions, and halibut CDQ revenue is not a large source of revenue for any region except AK Central West and AK Aleutians. Salmon revenue is an important contributor to owners residing in the Aleutians, Bristol Bay, Cook Inlet, Kodiak, and Southeast, and these regions' reliance on salmon is trending upwards. Crab harvest patterns changed most significantly in Norton Sound, Kodiak, and Anchorage/MatSu, where investment in the fishery increased.

\section{Total Regional Revenue}

To clearly identify intertemporal trends in the regional distribution of revenue, Figure 2 shows the percentages of total ex-vessel revenue from all fisheries according to the region of the vessel owner's city. Although the proportion of revenue for vessels owned outside of Alaska is large (approximately 60\%), allocation of revenue across regions appears to be largely stable. There is no clear trend of residents from outside of Alaska gaining share following the rationalization of the crab fleet in 2005 or the Amendment 80 fleet in 2008. In recent years, the larger share of revenue is captured by vessel owners located outside of Alaska; however this is a reversion to levels from the early years of the data. More populous regions like Anchorage and Seattle MSA gained shares, while southeast Alaska and other parts of Washington lost shares. The share of the most rural areas surrounding the Gulf of Alaska and the Bering Sea is stable.

\section{Regional Fishery Dependence}

While the revenue shares of each region may be stable, enclosure and rationalization policies may shift the composition of the fisheries that contribute to each region's revenue. Equivalent revenue levels from different fisheries could imply different levels of profitability and net benefits if the cost profiles differ considerably among fisheries, or, if the number of fisheries in which a region participates has dropped substantially, substitution possibilities to healthier and more abundant fisheries may be diminished. To investigate the possibility of such compositional changes, we calculate several Herfindahl-Hirschman Indexes (HHI) (Herfindahl, 1955; Hirschman, 1964). The HHI is a standard measure of concentration that takes on a value between 0 and 10,000 and is equal to the sum of squared market shares across entities in an industry. As such, it is very sensitive to movement away from complete concentration and relatively insensitive to changes in diverse industries. Kasperski and Holland (2013) used HHIs to examine how the diversity of fisheries in which a vessel participates relates to its year-overyear variation in profits, finding that it is riskier to be less diversified across fisheries; we explore these businesslevel effects below.

To assess whether some regions are becoming more dependent on individual fleets, Figure 3 shows the $\log$-HHI of each region's revenues across the distinct fleets studied. ${ }^{3}$ This is calculated for each region by

${ }^{3}$ We report natural log HHIs, with a maximum of 9.21 , to show changes in fisheries with numerous smaller vessels fisheries alongside industrial fisheries with fewer vessels. 


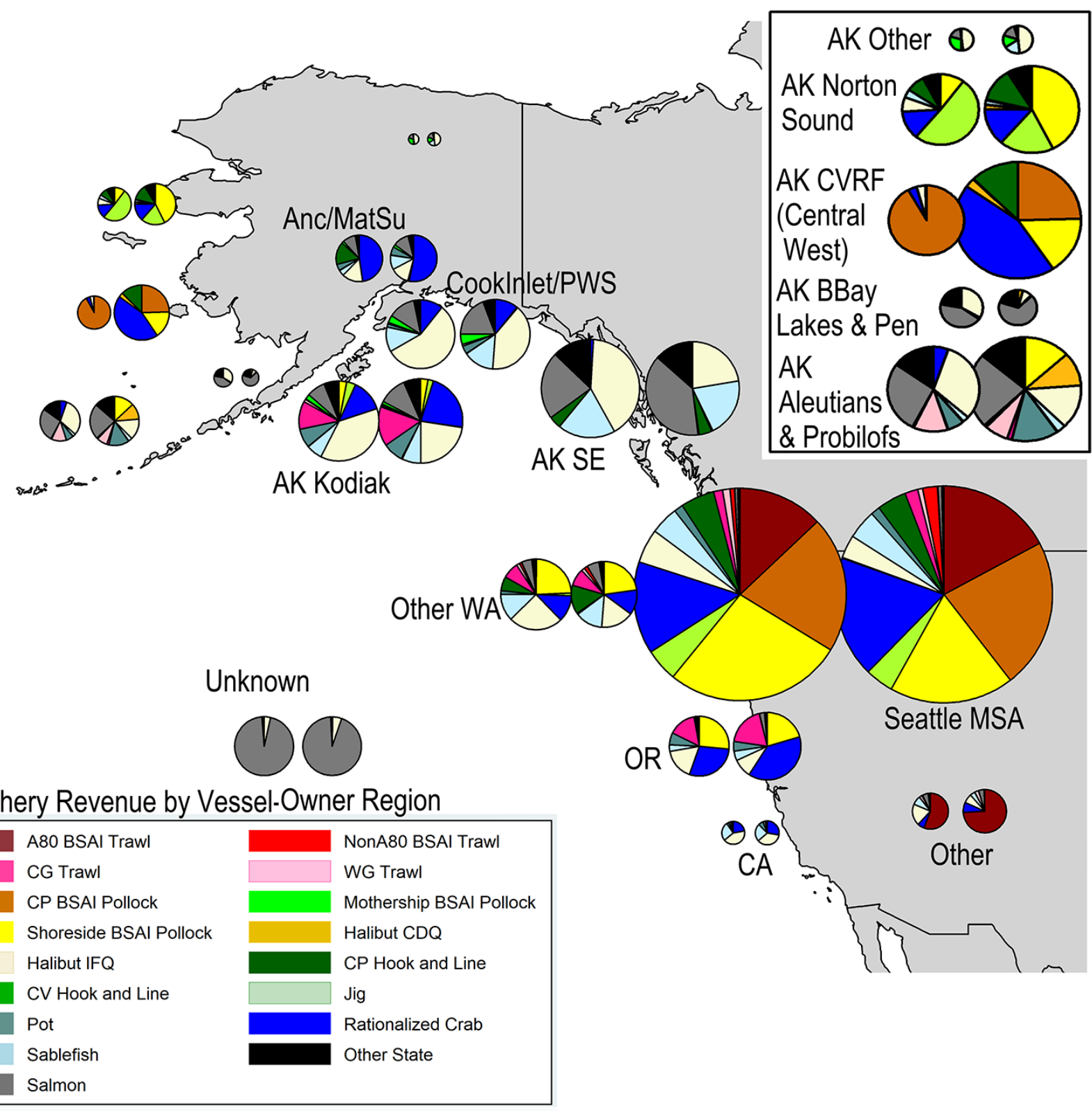

Figure 1.-Regional distribution of revenue by fishery in 2004-2006 (left pie in each region) and 2011-2013 (right pie in each region). Pie area is proportional to share of total revenue from all fisheries.

determining the region's total revenue from each fleet listed in Table 1, determining the share of the region's total fishery revenue associated with each fleet, and using that share as the basis for the HHI. Most regions do not show a strong trend, indicating they are as diversified across fleets as they were 10 years ago. This finding indicates there is not strong evidence that regions are forced into fewer or lower-valued fleets.

The high HHIs for AK Central West reflect a single CDQ group-owned pollock catcher-processor that accounts for more than $90 \%$ of revenue in some years. The increasing HHI for Bristol Bay reflects that it is increasingly concentrated within certain fleets. Kodiak has become less concentrated, as it was highly dependent on halibut and crab through the early 2000's but has diversified (while preserving revenue share in the crab fishery overall) by increasing its portfolio of jig and pot landings.

The regional level stability does obscure some shifts within individual fleets. In the newly rationalized crab fleet, the revenue shares of Anchor- 
age, Kodiak, and Norton Sound grow, while residents of southeast Alaska and the Aleutians no longer participate, and Washington's role is shrinking. Residents of southeast Alaska appear to be transitioning into the state's salmon fishery, as their share of salmon revenue is on the rise since the implementation of the crab quota system. Communities in the Aleutians increased their participation in the Central Gulf trawl fishery following the crab rationalization.

Within the fleets with CDQ allocations, there is a relatively large degree of variation in the vessels fishing CDQ allocation. For example, over the course of the CDQ halibut program, there has been a trend of increased revenue going to local harvesters in the Central Western and Aleutian regions in particular. Conversely, almost all vessels landing CDQ crab and groundfish quota were initially owned outside Alaska but there has been a strong trend of CDQ groups buying shares in vessels, especially those in close proximity to the fishery (see Supplemental Figure O for halibut CDQ fleet plots).

\section{Number of Vessels Participating}

Changes in fishery management can influence the number of vessels participating in a region, independent of the fisheries from which revenue is drawn. Figure 4 shows the number of fishing vessels in each region. The most numerous region, southeast Alaska, is losing vessels, corresponding with its drop in revenue share. Most other regions are experiencing a slight downward trend in the number of vessels, consistent with theories predicting an aggregate harvesting cost reduction through consolidation of harvesting operations over time after the introduction of catch shares. Some small and remote regions of rural Alaska, such as Norton Sound and Alaska Central West, are gaining vessels, where CDQ groups buy up capital and expand their harvesting operations. Although there is a concurrent decline in vessels in the neighboring region of Bristol Bay and Peninsula, the vessel level data indicate that the vessels moving into

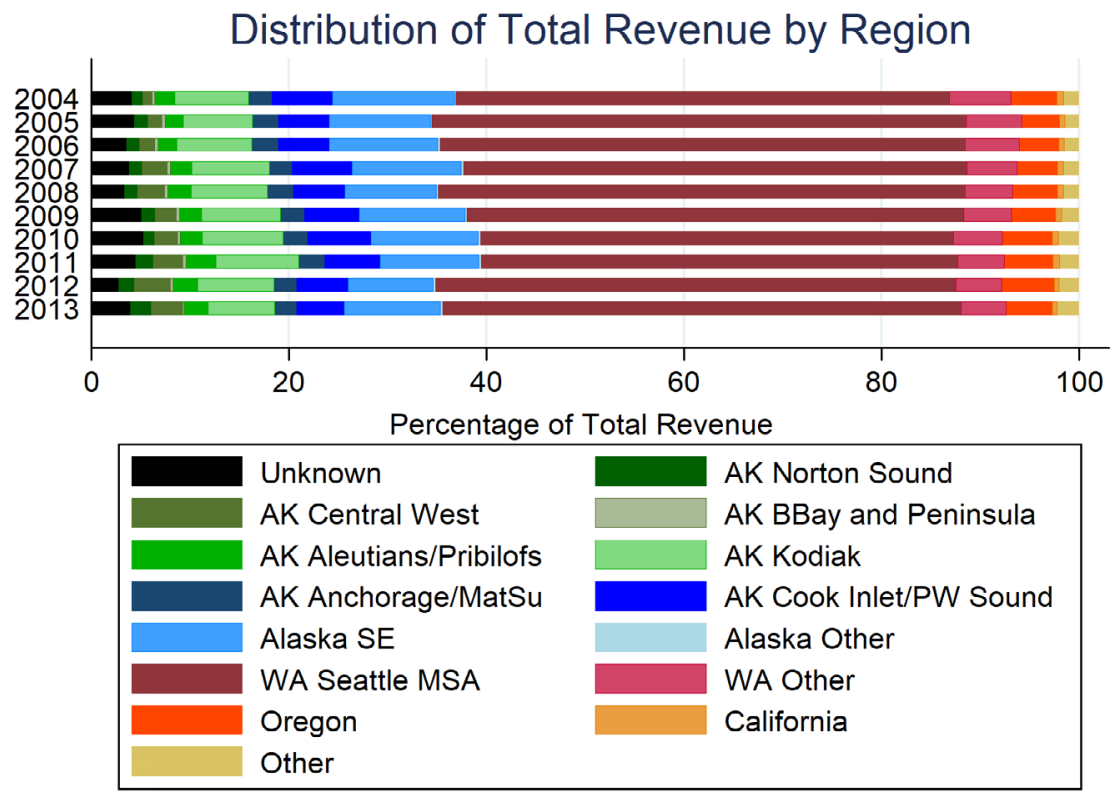

Figure 2.-Distribution of ex-vessel revenue by region.

Western Alaska and the CDQ regions are coming from outside; this may be attributable to frictions in labor and credit markets or existing capital being in poor condition.

A decline in vessels in one region could imply that revenue is leaving that region or that revenue is simply transferred to still-active vessels within the same region; these processes have different distributional implications outside the harvesting sector. Figure 5 shows the log-HHI of each region's vessel revenue, or how well diversified each region is across its vessels. This measure calculates total revenue for each vessel and determines each vessel's share of its region's total revenue, which is used as a basis for the HHI. Most regions have increased slightly in vessel revenue HHI, reflecting that most regions derive larger shares of their revenues from fewer vessels. Norton Sound is decreasing, partly reflecting the increase in the number of vessels seen above. AK Central West is decreasing, but excluding the single pollock catcher-processor, there is little trend.

While Figure 5 shows negligible trends in region-level HHIs, it may mask a concentration of revenue with- in communities from each region. We calculate the HHI for every community to reflect how diversified it is across vessels. This measure calculates total revenue for each vessel and determines the vessel's share of its community's total revenue, which is then used as a basis for the HHI. Slightly less than half the communities have HHIs approaching 10,000, reflecting that they have only one fishing vessel (Supplemental Figure T).

Among the communities with more vessels, at the 25th percentile of HHI, concentration changes negligibly, from 3,360 in 2004 (corresponding to a $45 / 30 / 25 / 5$ market share split, if there are four vessels), to 3,297 in 2013. This suggests that even at the individual community level, fishing communities are not becoming increasingly dependent on fewer and fewer vessels during the period of our data. This could still occur with a decreasing total number of vessels if the remaining smaller vessels are increasing their market share.

\section{Population Size Analysis}

Although Alaska regions have not seen a systematic decline in fishery revenue share or increasing reliance on 


\section{Regional Diversification Across Fisheries}

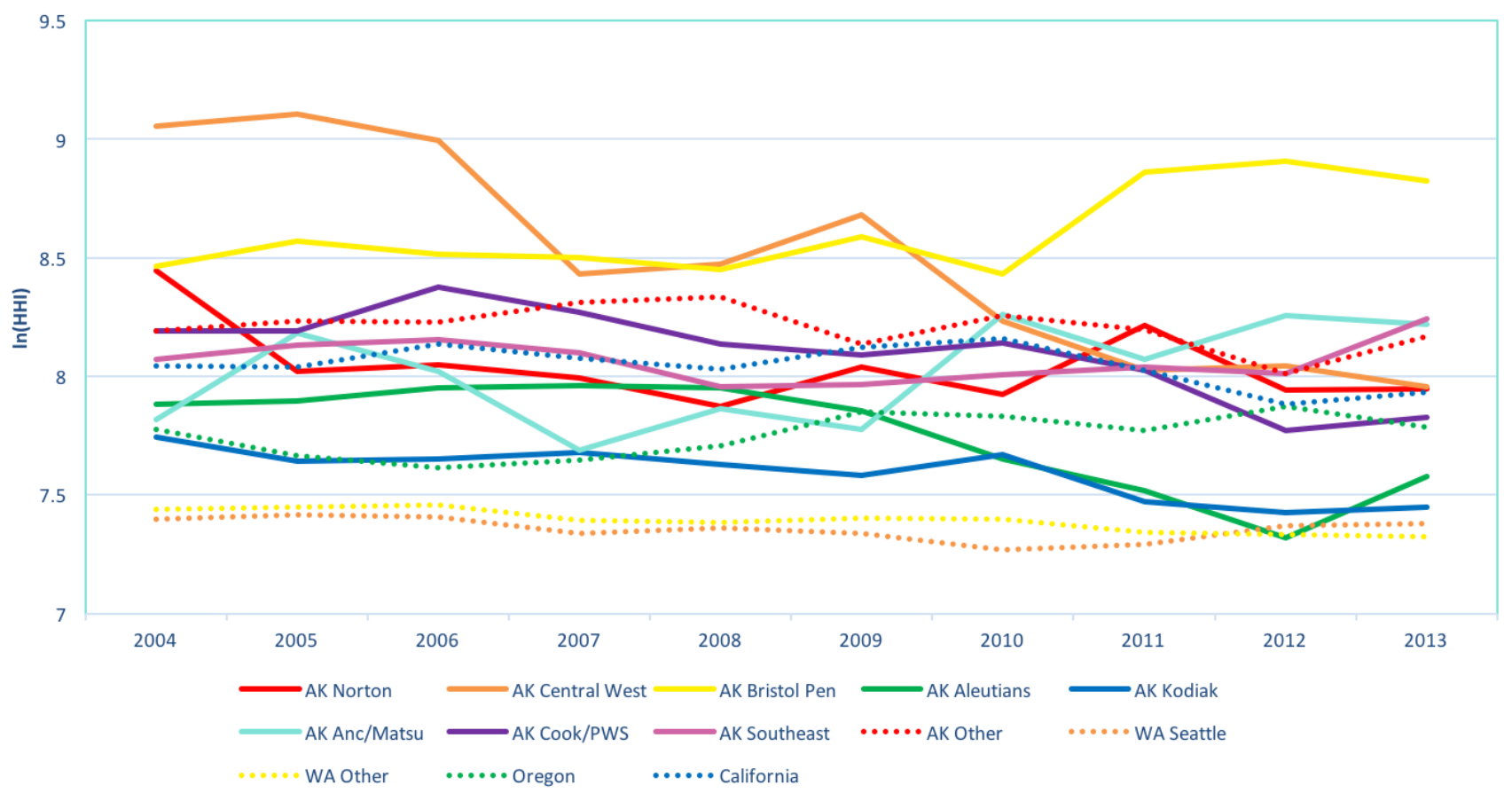

Figure 3.- - Log-HHI of region's revenue across fisheries, indicating how each region's fishery revenues (to resident owners) are concentrated across fisheries.

certain fisheries over the last decade, revenue may nevertheless be transferring out of small communities into larger towns within the same region. To avoid obscuring any movement from the smallest (and perhaps most vulnerable) communities to larger municipalities, we used census data to determine the population of each vessel-owner city, and assigned it to one of six bins for analysis. For comparability within the literature, we used the bins that Carothers et al. (2010) identified for small remote fishing communities with under 7,500 residents.

Figure 6 shows the distribution of total ex-vessel revenue from all fisheries according to the population of the vessel owner's city. Although the proportion of revenue that goes to vessels owned in cities with more than 25,000 residents is large (approximately $60 \%$ ), allocation of revenue across population bins is largely stable. From 2004 to 2008, large cities gained share from towns in the 2,500-7,500 bin. In
2009-10, when there was low revenue for pollock (majority of ownership in large cities), this trend reversed, but reemerged once pollock harvests increased again. All other population bins are relatively stable except for that of communities in the 1,500 2,500 bin, which has fallen from $3 \%$ of the total to $2 \%$.

When large communities gain even small amounts of the total share, it does appear to be at the expense of a handful of smaller towns, mainly located in southeast Alaska. However, this is largely reflecting features idiosyncratic to the individual fisheries represented in these community types, and any systematic trend is swamped by natural variation in TACs and prices. In many cases, these shifts represent the decisions of single individuals. Importantly, there is not a dramatic trend of residents from large cities gaining share following the crab rationalization, and all Amendment 80 vessels were owned by residents of the largest category at the outset of the program. Further, while the data from the last decade cannot illuminate what happened immediately following the pollock and halibut rationalizations, it does reflect that there is not a trend of continuing transfers of revenue share out of small communities.

To examine whether smaller communities are disproportionately concentrating revenues on fewer vessels, Figure 7 shows the natural logarithm of average community-level HHIs of vessel revenue within each of six size categories. The figure reveals a trend of increasing vessel revenue concentration within communities of every size relative to 2004. Mid-sized cities of 7,500-25,000 people are most stable, and medium-small cities of 1,500-2,500 people, which saw a significant decrease in the number of active vessels during the study period, saw the greatest increase in concentration. What we do not see, however, 


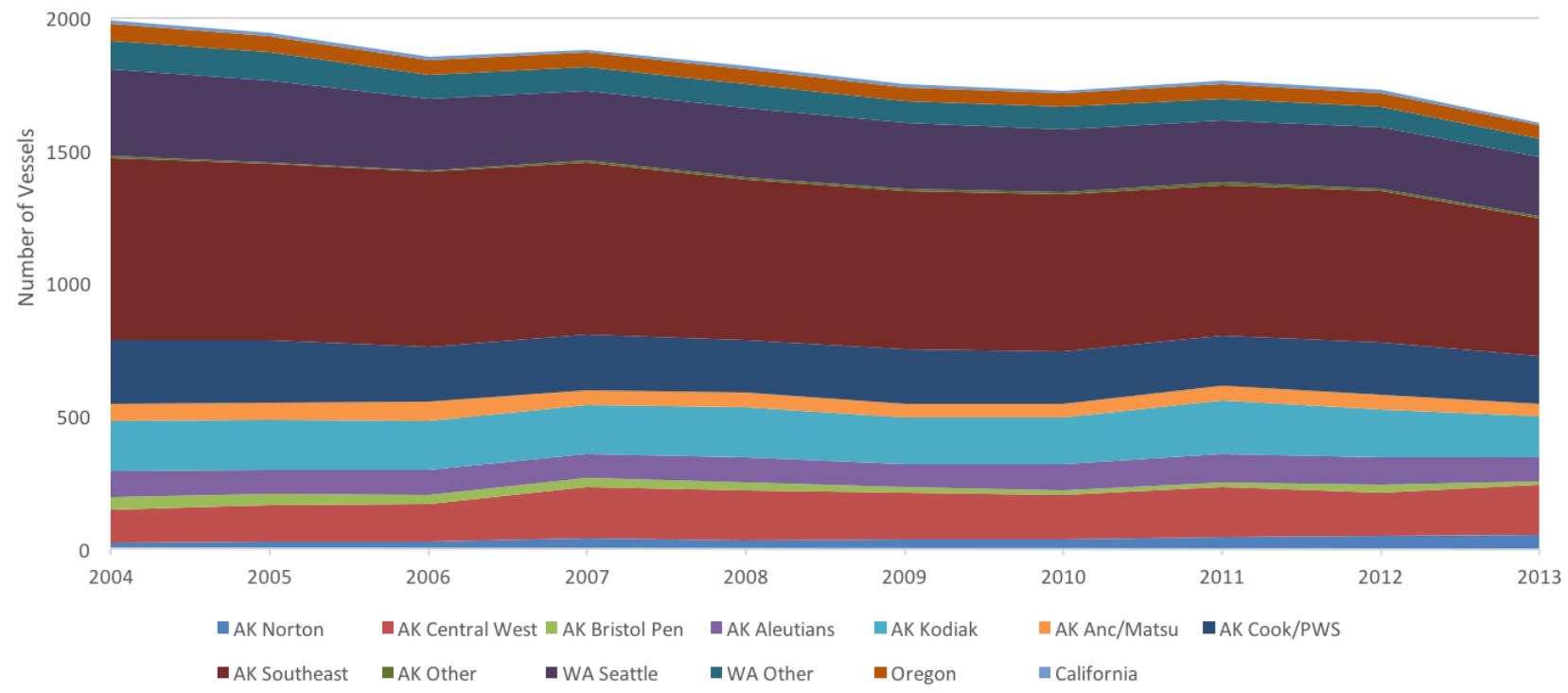

Figure 4.- Number of active vessels with revenue in some fishery in each region.

is a consistent pattern of small communities exhibiting greater or lesser degrees of diversification relative to larger communities. Rather, the smallest communities saw a sustained decrease in revenue concentration during 2006-10, reflecting a decreased share of halibut revenue as TACs declined, which is more recently being offset by increased village-based ownership of crab and pollock vessels, supported by CDQ ownership.

Although the revenue for these smallest communities may be stabilizing, our analysis of revenue flows does not illuminate the actual community-level impact of substituting a loss of direct revenue from individually owned vessels fishing halibut with indirect payments from increased CDQ ownership of larger vessels. This latter source of revenue is likely to provide much less direct benefit such as community block grants, crew employment opportunities, and increased local processing capacity.

To explore differences among com- munities within the same size category, Figure 8 presents violin plots representing the distribution of individual communities' vessel-revenue HHIs. The white dot in each violin indicates the median, the black bar the inner-quartile range, and the width of the gray field the smoothed density at that HHI; smoothing is required to protect confidentiality in communities with fewer than three vessels. Although these distributions are typically bimodal-reflecting numerous communities with one vessel - the changes in the median and positive mode can nonetheless be informative. There is no evidence of a median increase in concentration in cities between 1,500 2,500 and 25,000-250,000, even though some individual communities within those size bins may have exhibited some change. Small cities (under $1,500)$ show decreasing revenue concentration, while medium-sized cities show flat to increasing (especially 7,500-25,000) revenue concentration, meaning their owner income is con- centrated on fewer vessels. Increasing diversity in smaller cities could reflect participation in a greater range of fisheries or that they are losing some market share in the fisheries that made up the largest shares of their income.

Surprisingly, there is increasing concentration in medium-sized cities. There are several possible reasons that it may be easier for small operators to leave fishing in somewhat larger communities. First, it may be easier for large owners to buy out quota or permits from owners in medium-sized cities because they want to minimize transaction costs of acquisitions, and fishermen from medium-sized cities may have larger bundles of quota that are more appealing to large operators. Second, harvesters in medium-sized cities may have better outside (potentially non-fishing) labor market opportunities that make it more feasible for them to discontinue commercial fishing. Third, diversity in smaller western Alaska communities may be supported by CDQ corporations, whose missions 


\section{Regional Diversification Across Vessels}

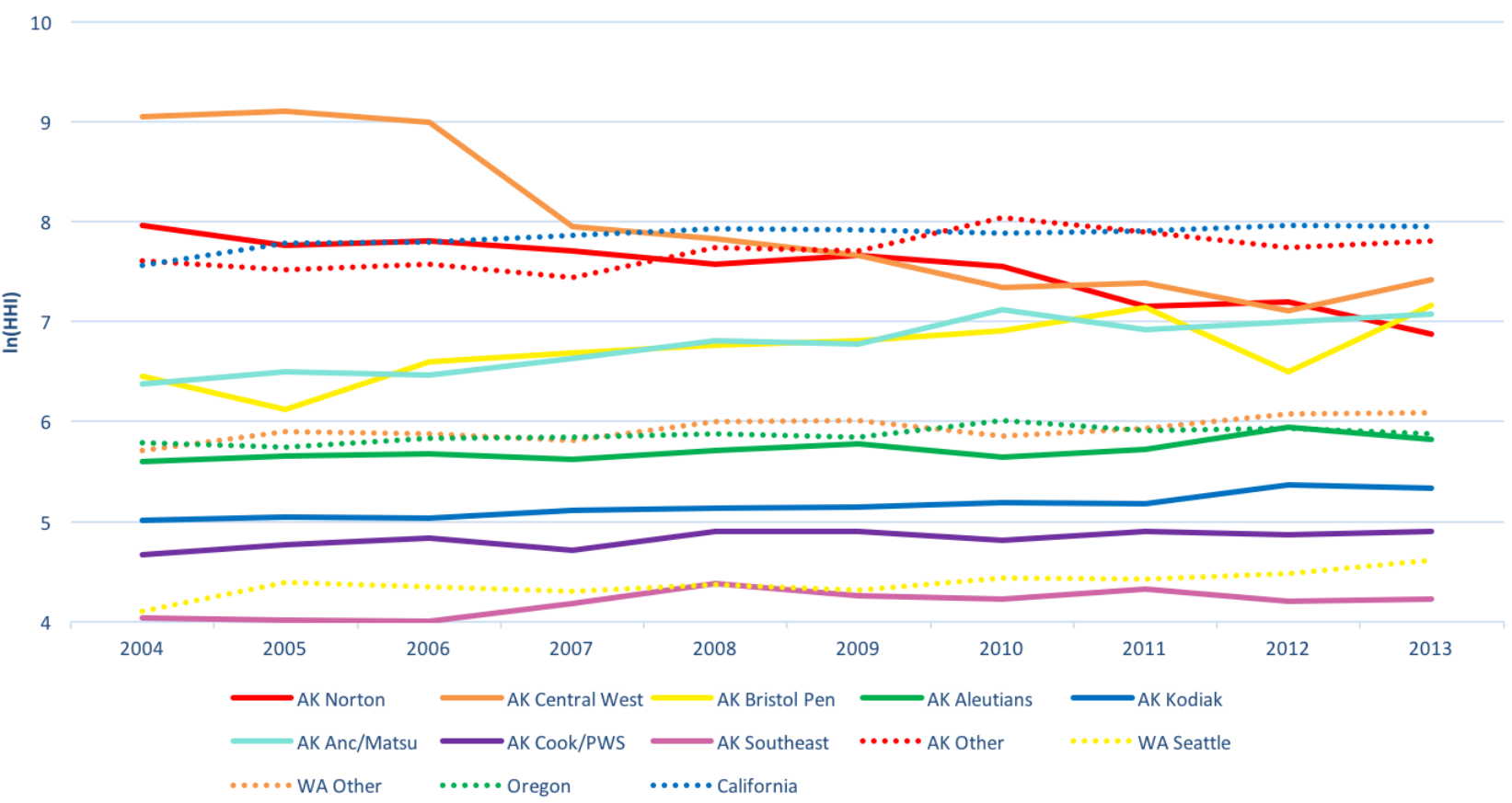

Figure 5.-HHIs reflecting the diversity of revenue across vessels owned in the region.

may lead them to attenuate the concentration trend that would otherwise prevail given their community size.

The aggregate analysis does obscure some variation in individual fisheries. In the newly rationalized crab fleet, the shares are largely stable although the smallest communities show slightly smaller shares, while the largest cities gained roughly $5 \%$. In the years immediately following crab rationalization, there was a more dramatic shift towards large cities, but in recent years communities with populations from 2,500 to 25,000 have gained share. The salmon fishery shows increasing revenue shifting to towns from 2,500 to 7,500 in population, with the gains coming from communities of "population size unknown"4. This fishery is the most diverse in terms of distribution of revenue by population size, and large cities are not dominant. In the halibut CDQ fishery there is a large

\footnotetext{
${ }^{4}$ This may be an artifact of improved data qual-
} ity and fewer "unknown" observations. degree of volatility once again, and the smallest communities have a much larger percentage of revenue in 2013, while participation across the spectrum has become more diverse (see Supplemental Material for individual fleet plots).

\section{Concentration of Vessel Operations Within Fisheries}

Up to this point in our analysis we have seen a relatively stable distribution of revenue across regions and within most community size classes. However, we have not examined whether particular vessels are becoming more concentrated in the fisheries that they pursue. That is, the observed stability may reflect that vessels could make similar amounts of revenue as in the past, but this revenue could be derived from a different and less diverse set of fisheries. This scenario could be disadvantageous if vessel owners are less able to distribute risk from stock fluctuations or market shocks by participating in multiple fisheries
(Kasperski and Holland, 2013). However, Figure 9 does not reflect much variation in the concentration of individual vessel revenues across fisheries. Therefore, at an aggregate level, vessels are not being squeezed out of individual fisheries, at least in ways that they are not able to replace by participating in other, new fisheries.

\section{Discussion}

The waters off Alaska host a range of valuable, relatively stable, and healthy fisheries providing immense value to the industries they support and to the U.S. economy as a whole. Examining the participating fleets and their revenue streams over the past decade suggests that real revenues have been growing and that over $60 \%$ of the revenues generated are associated with vessels whose owners reside outside of Alaska. Trends in non-Alaskan ownership are stable, however, reflecting historic interests particularly in the pollock, Amendment 80, and crab fleets. 
We analyze trends in revenues within the fleets along with changes in concentration in fishery participation across various dimensions to see if fishery enclosure policies have affected the spatial concentration of fishery revenues or the distribution across community types. In contrast to what some of the literature and stakeholder sentiment suggest - that limited access, catch share programs, and the forces of modernization cause local harvesters from small fishingdependent communities to consistently lose revenue to those with more capital from large cities out of stateour results show a more nuanced picture.

From 2004 through 2013, there has been no dramatic trend of revenue or vessel transfer from rural Alaska to Seattle; although the total number vessels especially in southeast Alaska and the Bristol Bay and Peninsula are decreasing. One interpretation is that a major effect of management's efforts toward enclosure has been to regulate the flow of effort and owner-

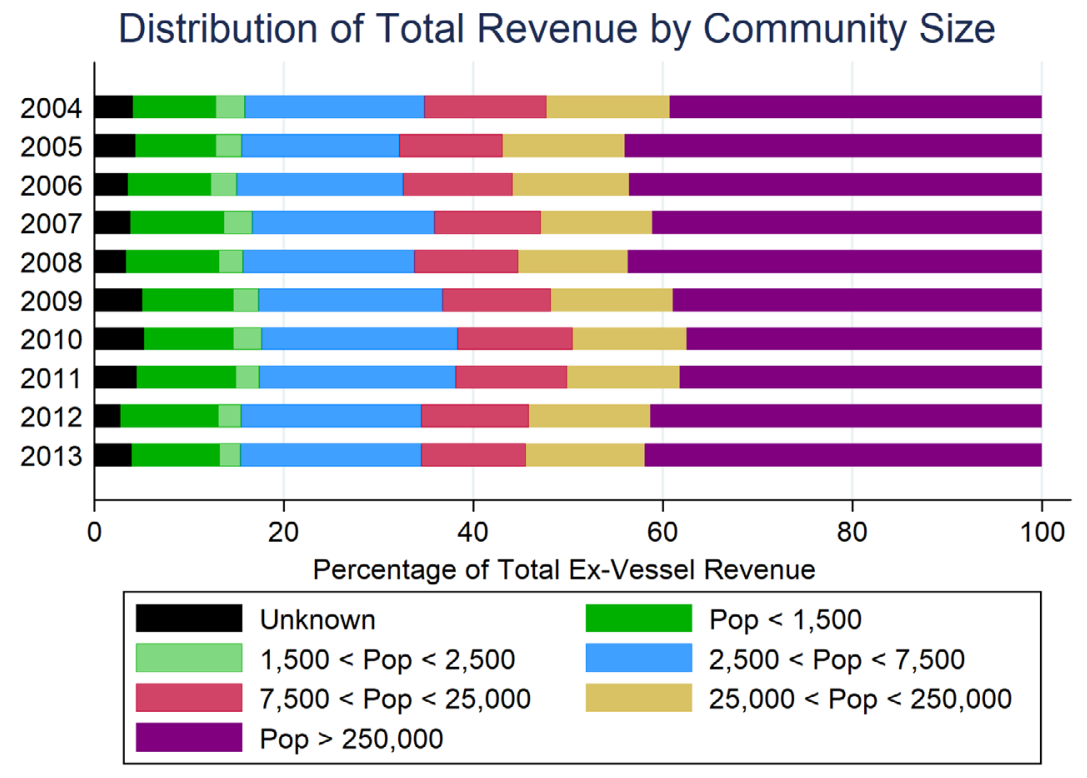

Figure 6.-Distribution of total ex-vessel revenue by the size category of the vessel owner's city.

\section{Community-Size Category Diversification Across Vessels}

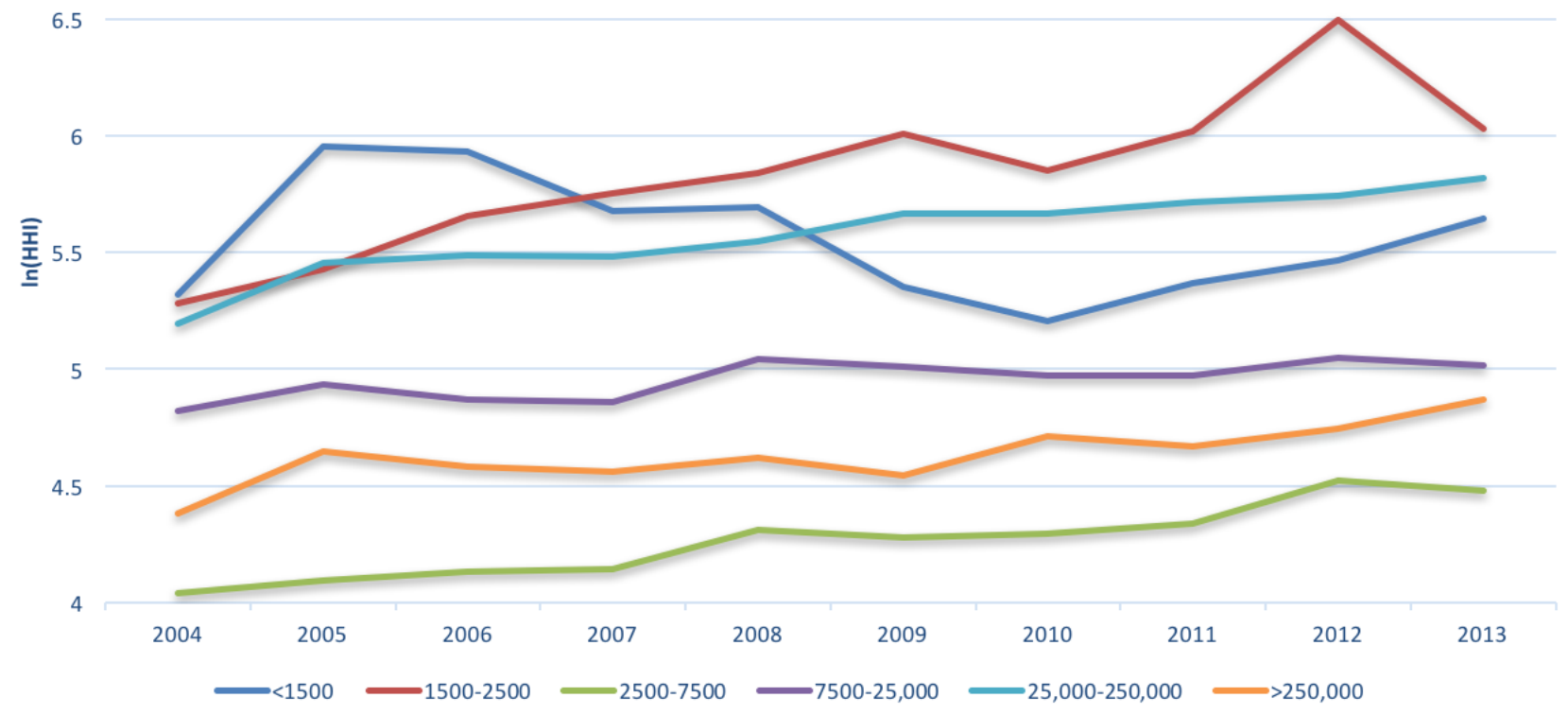

Figure 7.-HHIs of vessel revenue among communities of different sizes. 


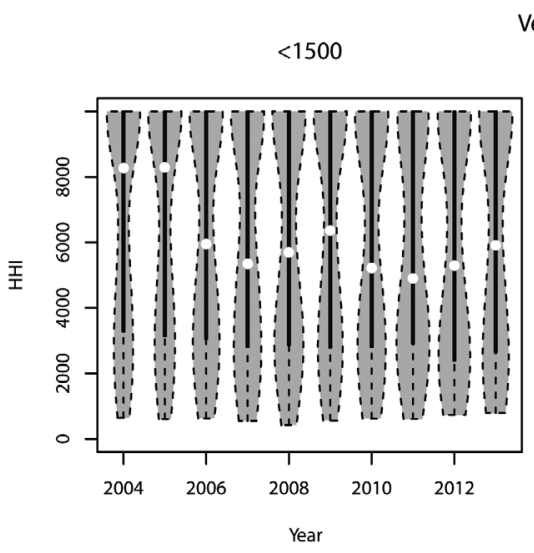

Vessel diversity within owner city: Vessel HHI by city size 1500-2500
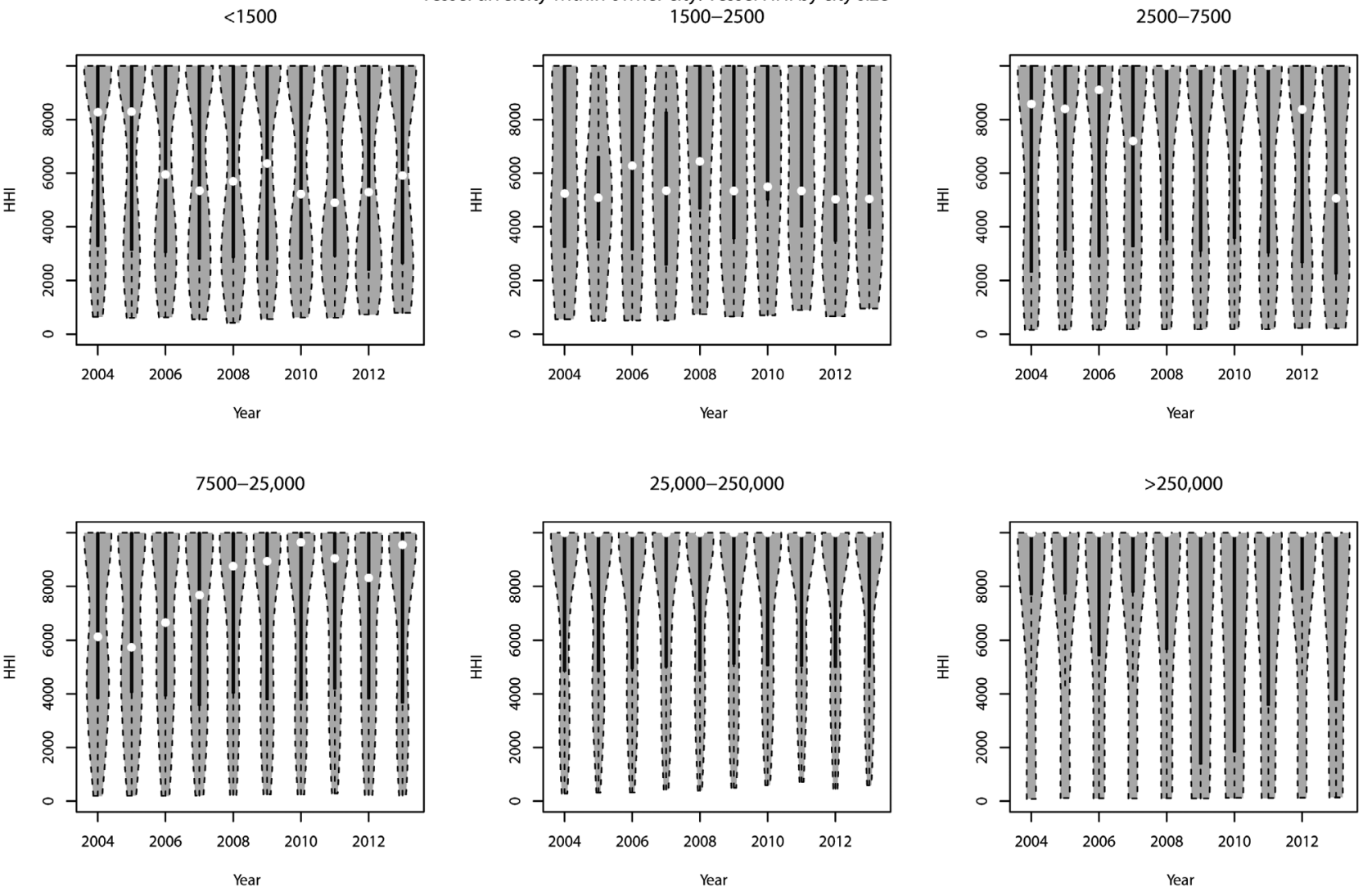

Figure 8.-HHI of ex-vessel revenue within each vessel owner city grouped by city size.

ship into fisheries, which in turn has stabilized the harvesting sector across fisheries.

The revenue share of the Seattle MSA fluctuates more than that of other regions, largely following the trends of the pollock stock during the period we study. In addition, there is no strong evidence that catch shares are forcing rural regions into a shrinking pool of low-value fisheries, because most regions are as diversified across fisheries as they were at the beginning of our sample.

We did find that some regions are becoming increasingly concentrated and reliant on the revenue generating capacity of a smaller set of vessels, which is likely a result of consolidation in the number of harvesting operations. Understanding the economic and social implications of this consolidation requires further data collection and is unfortunately beyond the scope of this analysis.

Knowing that regional stratification could obscure transfers from small and vulnerable communities to larger ones within the same region, we also examined the distribution of revenue across community sizes. Again, we found no strong trend of consolidation into large cities. There was evidence that the share of the smallest communities is slightly lower than in 2004, while the largest cities have gained share since 2009. Interestingly, the individual communities with $<1,500$ people show decreasing revenue concentration, while medium cities show flat to increasing revenue concentration suggesting that ownership transfers are occurring in medium-sized communities. This could be attributed to reduced transactions costs or increased outside labor market opportunities in medium-sized communities or the actions of CDQ groups in the smallest communities.

That our regional aggregate revenue analysis finds little evidence of spatiotemporal revenue redistribution across community sizes or regions may at first seem inconsistent with the literature on community dynamics following rationalization. There are two possible explanations. One is that the community-level dynamics occur partially, and only immediately following enclosure policies. Since we do not observe the initial impact of rationalization in the halibut/sablefish fleet, it is possible that there was a rapid consolidation of revenue outside Alaska that is the beyond the scope of our data range. This is not supported by results from the 20-yr review of the halibut and sablefish IFQ program which suggest that while community-level 


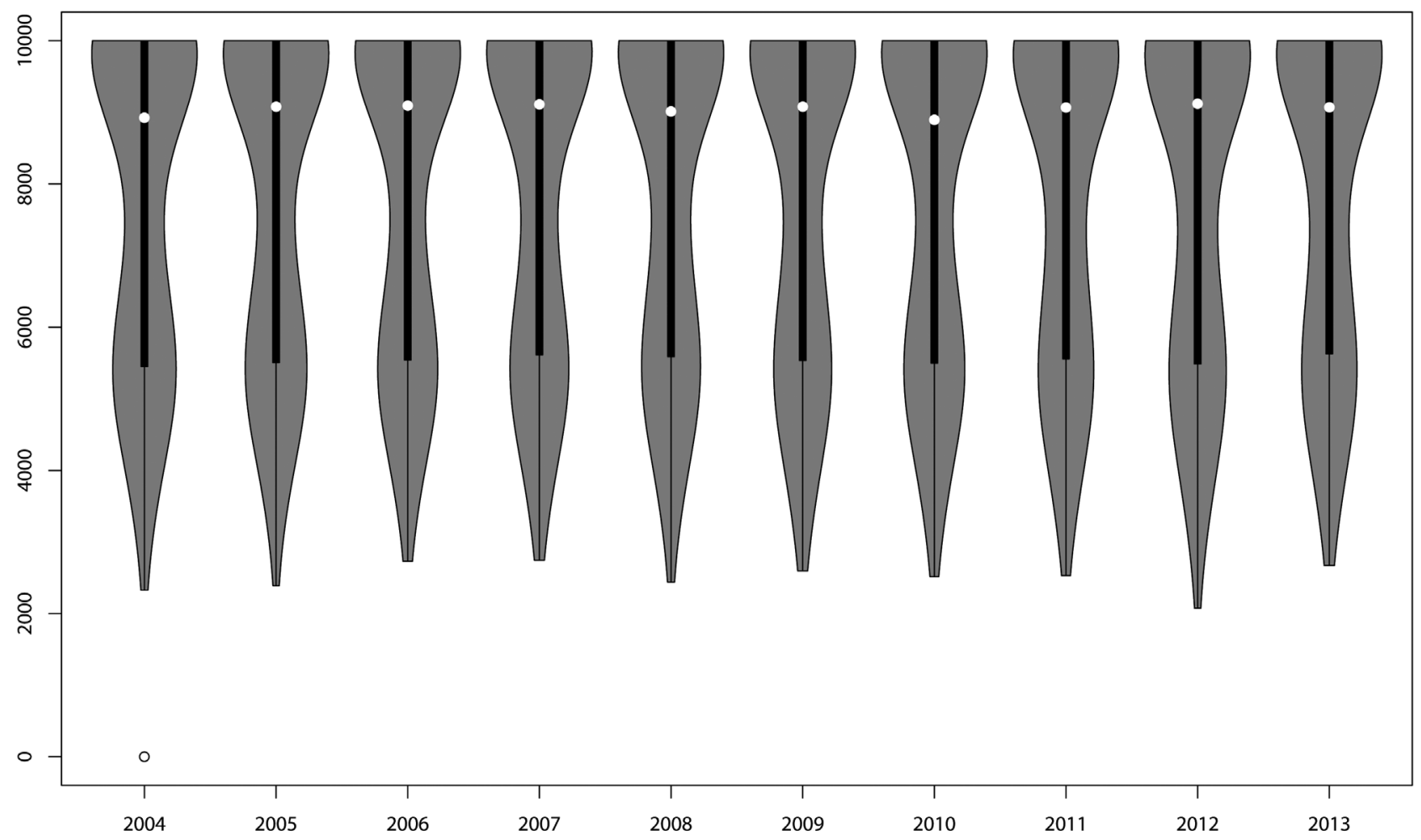

Figure 9.-Distribution of individual vessel HHIs across fisheries.

engagement in the harvesting sector varied across specific southeast Alaska ports, quota share ownership by Alaskan residents has been largely stable in these fisheries since implementation (NPFMC, 2016b:399).

Another possibility is that the CDQ program - the primary policy instrument designed to address the divestment in fishing activity in rural western Alaska-has been effective. Evidence in favor of the latter interpretation is that the most prominent regional trends are attributable to acquisition of quota and vessels by CDQ groups. This is especially relevant in the regions where the groups have focused on increasing their ownership stake in vessels and buying up quota shares. These actions may contribute direct revenue when local residents have the capital to participate directly, such as the halibut fleet, or less direct benefits in fleets such as crab and pollock. In our data, these actions translate as increasing dependence on a smaller number of fisheries, but also increased participation and local revenue.

Although the CDQ groups by definition represent rural western Alaska interests, it is possible that there are small operators within their boundaries who are unaffiliated with CDQ groups or small communities in southeast Alaska outside their boundaries who have not shared in the success of these groups. These groups may have seen their market share diminish through quota acquisition by those with greater access to capital, including both the industrialized fleets and the large CDQ corporations.

This exploratory study is primarily descriptive of trends and change in the distribution of revenues; however, it suggests several further avenues for analysis. First, it is important to note that this analysis does not construct a proper behavioral counterfactual that isolates the effects of management changes, before or during the period analyzed; it is unlikely the distribution of revenue would remain today what it was in 2004, given changes in fish stocks, technology, and the regional and global economies.

Second, our focus on linking revenue to vessel owner removes the complexities associated with non-fishing quota owners, who in many fisheries capture a significant portion of the fishery rent to spend in their residential communities. Location of residence need not have any relationship to the vessel's registration or area fished. Linking our analysis with information on quota ownership and transfers would clarify the extent to which vessel owner activity is reflective of the distribution of fishery benefits in quota fisheries.

While fisheries management, and even different participants in the management process, may have different objectives in implementing catch 
share programs, our results suggest that the primary distributional effects of the North Pacific Fishery Management Council's policies have been to stabilize participation in the fishery from 2004 to 2013. Indeed, the most dramatic shifts in revenue distributions during the study period were the reduction in vessel participation following rationalization in the crab fishery and the unexplained decline in the halibut TAC, neither of which resulted in changes in the distribution of revenue in the regions most affected. Thus, if the intent of these policies was to institutionalize the historic patterns of participation by incumbent harvesters, they have been largely successful.

\section{Literature Cited}

Abbott, J., B. Garber-Yonts, and J. E. Wilen. 2010. Employment and remuneration effects of IFQs in the Bering Sea/Aleutian Islands crab fisheries. Mar. Res. Econ. 25(4):333-354. (doi: https://doi. org/10.5950/0738-1360-25.4.333).

Carothers, C. 2008. Rationalized out: discourses and realities of fisheries privatization in Kodiak, Alaska. In M. Lowe and C. Carothers (Editors), Enclosing the fisheries: people, places, and power. Am. Fish. Soc. Symp. 69:55-74.

, D. Lew, and J. Sepez. 2010. Fishing rights and small communities: Alaska halibut IFQ transfer patterns. Ocean Coast. Manage. 53:518-523. (doi: https://doi. org/10.1016/j.ocecoaman.2010.04.014).

Costello, C., S. Gaines, and J. Lyman. 2008. Can catch share fisheries prevent collapse? Science 19(321)5896:1,678-1,681. (doi: https:// doi.org/10.1126/science.1159478).

Felthoven, R. 2002. Effects of the American Fisheries Act on capacity, utilization and technical efficiency. Mar. Res. Econ. 17(3):181-205. (doi: https://doi.org/10.1086/ mre.17.3.42629363).

Fissel, B., M. Dalton, R. Felthoven, B. GarberYonts, A. Haynie, S. Kasperski, J. Lee, D. Lew, A. Santos, C. Seung, and K. Sparks. 2015. Stock assessment and fishery evaluation report for the groundfish fisheries of the Gulf of Alaska and Bering Sea/Aleutian Islands area: economic status of the groundfish fisheries off Alaska, 2014. U.S. Dep. Commer., NOAA, Natl. Mar. Fish. Serv., Alaska Fish. Sci. Ctr., Resour. Ecol. Fish. Manage. Div., Econ. Soc. Sci. Res. Prog., 406 p. (Online at https://www.afsc.noaa.gov/refm/ docs/2015/economic.pdf)

Gho, M., N. Free-Sloan, K. Iverson, and K. Schelle. 2012. Changes in the distribution of Alaska's commercial fisheries entry permits. In C. Carothers, K. R. Criddle,
C. P. Chambers, P. J. Cullenberg, J. A. Fall, A. Himes-Cornell, J. Petter Johnsen, N. S. Kimball, C. R. Menzies, and E. S. Springer (Editors), Fishing people of the north: cultures, economies and management responding to change. Alaska Sea Grant Coll. Prog. Rep. AJ-SG-1203, 314 p. (doi: https://doi. org/10.4027/fpncemrc.2012).

Herfindahl, O. 1955. Comment on Rosenbluth's measures of concentration. In G. Stigler (Editor), Business concentration and price policy, 505 p. Princeton Univ. Press, Princeton, N.J.

Himes-Cornell, A., and S. Kasperski. 2016. Using indicators to aid in the assessment of vulnerability and resiliency in Alaskan fishing communities. Coast. Manage. 44(1):36-70.

Hirschman, A. 1964. The paternity of an index. Am. Econ. Rev. 54(5):761-762.

Holland, D. 2000. Fencing the fisheries commons: regulatory barbed wire in the Alaskan groundfish fisheries. Mar. Res. Econ. 15(2):141-149. (doi: https://doi.org/10.1086/ mre.15.2.42629297).

E. Thunberg, J. Agar, S. Crosson, C. Demarest, S. Kasperski, L. Perruso, E. Steiner, J. Stephen, A. Strelcheck, and M. Travis. 2015. U.S. catch share markets: a review of data availability and impediments to transparent markets. Mar. Pol. 57:103-110. (doi: https://doi.org/10.1016/j. marpol.2015.03.027).

C. Speir, J. Agar, S. Crosson, G. DePiper, S. Kasperski, A. Kitts, and L. Perruso. 2017. Impact of catch shares on diversification of fishers' income and risk. Proc. Natl. Acad. Sci. USA 114(35):9,302-9,307 (doi: https://doi.org/10.1073/pnas.1702382114).

and S. Kasperski. 2016. The impact of access restrictions on fishery income diversification of U.S. west coast fishermen. Coast. Manage. 44(5):1-12. (doi: https://doi.org/10. 1080/08920753.2016.1208883)

Kasperski, S., and D. Holland. 2013. Income diversification and risk for fishermen. Proc. Natl. Acad. Sci., USA 110(6):2,076-2,081.

Knapp, G., M. Guetttabi, and S. Goldsmith. 2013. The economic importance of the Bristol Bay salmon industry. Inst. Soc. Econ. Res. Rep., 86 p. (prep. for the Bristol Bay Reg. Seafood Develop. Assoc.) (http://www. iser.uaa.alaska.edu/Publications/2013_04TheEconomicImportanceOfTheBristolBaySalmonIndustry.pdf) accessed 19 July 2016.

NMFS. 2017. Fisheries of the United States, 2016. U.S. Dep. Commer., NOAA Curr. Fish. Stat. 2016, 147 p. (avail. at https:// www.fisheries.noaa.gov/resource/document/ fisheries-united-states-2016-report).

NMFS/AKRO. 2016a. Environmental Assessment/ Regulatory Impact Review for Proposed Amendment 110 to the Fishery Management Plan for Groundfish of the Bering Sea and Aleutian Islands Management Area Bering Sea Chinook Salmon and Chum Salmon Bycatch Management Measures. 351 p., accessed Sept. 2017 (avail. at https://alaskafisheries.noaa.gov/sites/default/files/analyses/bsail10finalearir.pdf)

2016b. Environmental Assess-

ment/ Regulatory Impact Review/Initial
Regulatory Flexibility Analysis for Amendment 111 to the Fishery Management Plan for Groundfish of the Bering Sea/Aleutian Islands Management Area: Revise Bering Sea/ Aleutian Islands Halibut Prohibited Species Catch Limits. 504 p., accessed Sept. 2017 (avail. at https://alaskafisheries.noaa.gov/ sites/default/files/analyses/finalbsai111 earirirfa0116.pdf).

NMFS Alaska Regional Office. Nd. Fisheries catch and landings reports: IFQ halibut/sablefish. Accessed 19 July 2016 (avail. at (https://alaskafisheries.noaa.gov/ fisheries-catch-landings?tid $=287$ )

NPFMC. 2012. Fishing fleet profiles. N. Pac. Fish. Manage. Counc., 72 p., (avail. at http:// www.npfmc.org/wp-content/PDFdocuments resources/FleetProfiles412.pdf).

2016a. Ten-year program review

for the crab rationalization management program in the Bering Sea/Aleutian Islands. N. Pac. Fish. Manage. Counc., 249 p., (avail. at https://www.npfmc.org/wp-content/PDFdocuments/catch_shares/Crab/Crab10yrReview Final2017.pdf)

2016b. Twenty-year review of the

Pacific halibut and sablefish individual fishing quota management program. Final draft, Dec. 2016. N. Pac. Fish. Manage. Counc., 474 p., (avail. at https://www.npfmc.org/wpcontent/PDFdocuments/halibut/IFQProgramReview_417.pdf).

Scheld, A., and C. Anderson. 2014. Market effects of catch share management: the case of New England multispecies groundfish. ICES J. Mar. Sci. 71(7):1,835-1,845 (https://doi. org/10.1093/icesjms/fsu001).

Sethi, S., W. Riggs, and G. Knapp. 2014a. Metrics to monitor the status of fishing communities: an Alaska state of the state retrospective 1980-2010. Ocean Coast. Manage. 88:21-30. (doi: https://doi.org/10.1016/j. ocecoaman.2013.11.007)

M. Reimer, and G. Knapp. 2014b.

Alaskan fishing community revenues and the stabilizing role of fishing portfolios. Mar. Pol. 48:134-141. (doi: https://doi.org/10.1016/j. marpol.2014.03.027).

Szymkowiak M., and A. Himes-Cornell. 2018. Fisheries allocations for socioeconomic development: Lessons learned from the Western Alaska Community Development Quota (CDQ) Program. Ocean Coast. Manage. 155:40-49. (doi: https://doi. org/10.1016/j.ocecoaman.2018.01.014).

Thebaud, O., J. Innes, and N. Ellis. 2012 From anecdotes to scientific evidence? A review of recent literature on catch share systems in marine fisheries. Front. Ecol Environ. 10(8):433-437. (doi: https://doi. org/10.1890/110238)

van Putten, I., and C. Gardner. 2010. Lease quota fishing in a changing rock lobster industry. Mar. Pol. 34(5):859-867. (doi: https://doi. org/10.1016/j.marpol.2010.01.008).

Witherell, D., C. Pautzke, and D. Fluharty. 2000 An ecosystem-based approach for Alaska groundfish fisheries. ICES J. Mar. Sci 57:771777. (doi: https://doi.org/10.1006/jmsc. 2000. 0719) 